\title{
Human gastric epithelial cells contribute to gastric immune regulation by providing retinoic acid to dendritic cells
}

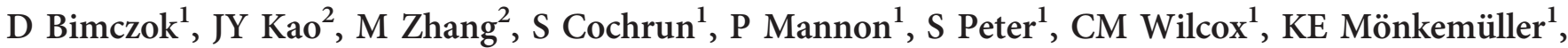 \\ PR Harris ${ }^{3}$, JM Grams ${ }^{4}$, RD Stahl ${ }^{4}$, PD Smith ${ }^{1,5}$ and LE Smythies ${ }^{1}$
}

Despite the high prevalence of chronic gastritis caused by Helicobacter pylori, the gastric mucosa has received little investigative attention as a unique immune environment. Here, we analyzed whether retinoic acid (RA), an important homeostatic factor in the small intestinal mucosa, also contributes to gastric immune regulation. We report that human gastric tissue contains high levels of the RA precursor molecule retinol (ROL), and that gastric epithelial cells express both RA biosynthesis genes and RA response genes, indicative of active RA biosynthesis. Moreover, primary gastric epithelial cells cultured in the presence of ROL synthesized RA in vitro and induced RA biosynthesis in co-cultured monocytes through an RA-dependent mechanism, suggesting that gastric epithelial cells may also confer the ability to generate RA on gastric dendritic cells (DCs). Indeed, DCs purified from gastric mucosa had similar levels of aldehyde dehydrogenase activity and RA biosynthesis gene expression as small intestinal DCs, although gastric DCs lacked CD103. In H. pylori-infected gastric mucosa, gastric RA biosynthesis gene expression was severely disrupted, which may lead to reduced RA signaling and thus contribute to disease progression. Collectively, our results support a critical role for RA in human gastric immune regulation.

\section{INTRODUCTION}

Despite the high prevalence of chronic gastritis caused by Helicobacter pylori and the serious complications that can arise from $H$. pylori infection, the gastric mucosa has received little investigative attention as a unique immunological compartment. H. pylori shares traits of both pathogenic and commensal bacteria, ${ }^{1}$ and we recently showed that soluble mediators present in gastric lamina propria suppress the adaptive response to $H$. pylori through downregulation of dendritic cell (DC) function. ${ }^{2}$ Moreover, increasing evidence indicates that the human gastric mucosa also harbors a diverse microflora of true gastric commensal bacteria that does not induce an inflammatory immune response. ${ }^{3,4}$ These findings suggest that homeostatic immune mechanisms that support tolerance to colonizing microbes are likely present in human gastric mucosa.
Retinoic acid (RA) is a key homeostatic factor in human small intestine, and RA synthesis by small intestinal $\mathrm{CD} 103^{+}$ DCs is considered essential for the induction of T-cell expression of gut-homing receptors CCR 9 and $\alpha 4 \beta 7$ and for the conversion of naive T cells to FoxP3 regulatory T cells. ${ }^{5-8}$ Thus, DC RA production is thought to contribute to intestinal tolerance to commensal bacteria and dietary antigens. RA is generated from retinol (ROL, vitamin A) through a two-step reaction, the first step involving oxidation of ROL to retinal by a retinol dehydrogenase, most importantly $\mathrm{RDH} 10$, and the second step involving further oxidation of retinal to all-trans RA by tissue-specific isoforms of retinaldehyde dehydrogenase, RALDH1, RALDH2, and RALDH3. ${ }^{9}$ The ability of intestinal DCs to generate RA depends on tissue-specific crosstalk between epithelial cells and DCs. Thus, previous studies in the mouse have shown that intestinal DCs acquire the ability to

${ }^{1}$ Department of Medicine, University of Alabama at Birmingham, Birmingham, Alabama, USA. ${ }^{2}$ Division of Gastroenterology, Department of Internal Medicine, University of Michigan Health System, Ann Arbor, Michigan, USA. ${ }^{3}$ Department of Pediatrics, Gastroenterology and Nutrition, School of Medicine, Pontificia Universidad Católica de Chile, Santiago, Chile. ${ }^{4}$ Department of Surgery, University of Alabama at Birmingham, Birmingham, Alabama, USA and ${ }^{5}$ VA Medical Center Research Service, Birmingham, Alabama, USA. Correspondence: LE Smythies (lesmy@uab.edu) 
synthesize RA from adjacent RA-producing intestinal epithelial cells through a positive feedback loop that involves the RALDH2 gene aldh1a2. ${ }^{6,10}$ In murine DCs, an RA response element half-site was recently identified that mediates RAdependent induction of Aldh1a2 through binding of the RARA receptor (RAR)- $\alpha /$ RXR- $\alpha$ receptor complex. ${ }^{11}$ RA biosynthesis in human gastric mucosa has been described previously, ${ }^{12}$ but the cells that produce RA have not been identified, and whether RA contributes to gastric mucosal immune regulation is not known.

The goal of this study was to determine whether RAdependent mechanisms could contribute to gastric homeostasis. Using primary human cells isolated from mucosal tissue samples, we show that both gastric epithelial cells and DCs were as efficient at RA biosynthesis as small intestinal epithelial cells and DCs, although gastric DCs lacked CD103 expression. Moreover, primary human gastric epithelial cells drove RA biosynthesis in co-cultured monocytes through an RAdependent mechanism, indicating that gastric epithelial cells may confer the ability to synthesize RA on gastric DCs. Collectively, these data suggest a role for RA in human gastric immune regulation.

\section{RESULTS}

\section{Gastric epithelial cells synthesize RA}

RA synthesis by small intestinal epithelial cells contributes to homeostasis in intestinal mucosa through RA-mediated differentiation of tolerogenic mucosal DCs that, in turn, induce regulatory $\mathrm{T}$ cells with mucosal-homing capacity. ${ }^{6}$ To establish whether epithelial cells in human gastric mucosa similarly contribute to gastric immune regulation through RA synthesis, we first analyzed primary gastric epithelial cells for their ability to convert ROL to RA. Normal phase highperformance liquid chromatography (HPLC) analysis revealed that supernatants from gastric epithelial cells cultured for $24 \mathrm{~h}$ in the presence of ROL $(2 \mu \mathrm{M})$ contained $43.4 \pm 4.3 \mathrm{pmol} \mathrm{ml}^{-1}$ of RA, as well as low levels of retinal (Table 1). Notably, the total amount of RA synthesized by the epithelial cells was likely higher than the amount measured, because a proportion of the RA may have been metabolized or degraded before the analysis. In contrast, neither RA nor retinal synthesis was detected in epithelial cell cultures without exogenous ROL (Table 1) or where ROL was added to cell culture medium that did not contain epithelial cells (data not shown).

RA synthesis requires conversion of ROL to retinal by a retinol dehydrogenase and, as a second step, the conversion of retinal to RA by (retin)aldehyde dehydrogenases. ${ }^{7}$ To determine whether gastric epithelial cells have access to a local source of ROL in vivo, fresh specimens of healthy human gastric mucosa were analyzed for the presence of ROL by HPLC. As a reference, donor-matched samples of small intestinal mucosa, which contains high levels of ROL, ${ }^{13}$ were analyzed in parallel. Surprisingly, ROL was present in gastric mucosa at significantly higher levels than in intestinal mucosa $(224.3 \pm 16.3$ vs. $138.1 \pm 14.4 \mathrm{pmol} \mathrm{g}^{-1}, P=0.002, n=7$; Figure 1a). We next
Table 1 Primary human gastric epithelial cells synthesize RA from retinol

\begin{tabular}{lccc}
\hline & $\begin{array}{c}\text { Retinol } \\
\left(\mathrm{pmol} \mathrm{ml}^{-1}\right)\end{array}$ & $\begin{array}{c}\text { Retinal } \\
\left(\mathrm{pmol} \mathrm{ml}^{-1}\right)\end{array}$ & $\begin{array}{c}\mathrm{RA} \\
\left(\mathrm{pmol} \mathrm{ml}^{-1}\right)\end{array}$ \\
\hline Epithelial cells & $44.0 \pm 4.9$ & $\mathrm{ND}$ & $\mathrm{ND}$
\end{tabular}

Epithelial cells + retinol $(2 \mu \mathrm{M}) \quad 1,043.0 \pm 97.9 \quad 6.8 \pm 0.4 \quad 43.4 \pm 4.3$

Abbreviations: HPLC, high-performance liquid chromatography; ND, not detected; $\mathrm{RA}$, retinoic acid.

Retinoids were detected by normal phase HPLC in supernatants of gastric epithelial cell monolayers cultured in the presence of $2 \mu \mathrm{M}$ retinol for $24 \mathrm{~h}, n=5$.

analyzed the expression of $\mathrm{RDH} 10$, the relevant retinol dehydrogenase, ${ }^{14}$ and of ALDH1A1, the epithelial cell-predominant isoform of ALDH, in freshly isolated human gastric epithelial cells and donor-matched small intestinal epithelial cells (Figure 1b) and showed that both RDH10 and ALDH1A1 were expressed at significantly higher levels in gastric compared with intestinal epithelial cells (Figure 1c). In addition, gastric epithelial cell expression of $R A R-\beta, R A R-\gamma$ and cellular RAbinding protein $(C R A B P) 2$ was also significantly higher than that of intestinal epithelial cells, whereas no difference was detected for expression of RAR- $\alpha$ (Figure 2). $R A R-\alpha, R A R-\beta$, $R A R-\gamma$, and $C R A B P 2$ are RA target genes that are directly upregulated by $\mathrm{RA} ;{ }^{15}$ high expression levels are therefore indicative of high availability of RA in the gastric mucosa. Surprisingly, expression of TGM2, an RA-response gene important in macrophages, ${ }^{16,17}$ was higher in intestinal than gastric epithelial cells (Figure 2). However, the human TGM2 promoter is extremely responsive to a large variety of stimuli, ${ }^{18}$ including transforming growth factor- $\beta$, which is present at high levels in intestinal mucosa, but very low levels in gastric mucosa, ${ }^{2}$ offering a potential explanation for the discordant TGM2 expression in gastric vs. intestinal epithelium. Taken together, our data strongly suggest that human gastric epithelium has a similar capacity to generate RA as small intestinal epithelium.

\section{Retinoid metabolism differs between gastric and intestinal mucosa}

The small intestine is generally considered a privileged site for RA synthesis, because intestinal epithelial cells have access to luminal ROL or retinal derived from bile and from intestinal digestion of dietary vitamin A (retinyl esters) and carotenoids. ${ }^{19}$ Moreover, studies in mice have shown that small intestinal mucosa contains higher levels of ROL than other organs such as spleen and peripheral lymph nodes. ${ }^{13}$ In contrast, dietary vitamin A is not metabolized to ROL in the human stomach, ${ }^{20}$ and an additional source of free ROL in the gastric mucosa has not been identified. Therefore, to determine whether the high gastric ROL levels (Figure 1a) were due to a higher sequestration of ROL in the gastric mucosa, we analyzed the expression of cellular ROL-binding proteins (CRBPs) in gastric and intestinal mucosa and isolated epithelial cells. CRBPs are cytoplasmic chaperones that bind and then channel ROL through reactions of RA and retinyl ester synthesis while protecting it from degradation through other pathways. ${ }^{21}$ 
a

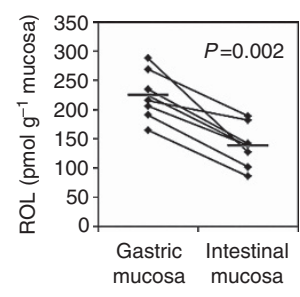

b

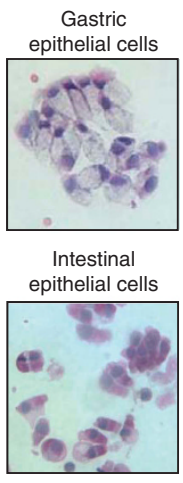

C

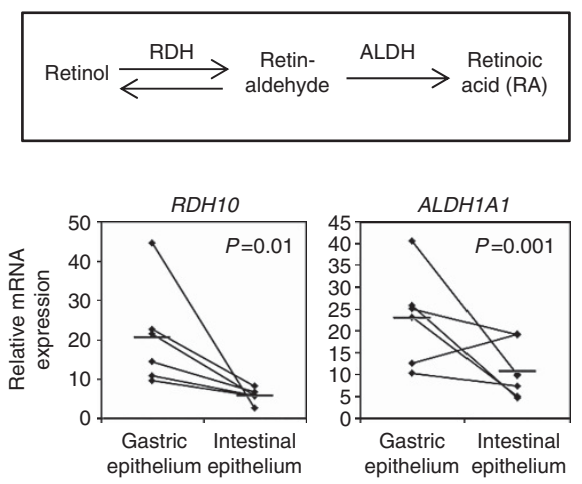

Figure 1 Retinoic acid (RA) biosynthesis by human gastric epithelial cells. (a) Tissue levels of retinol in human gastric and small intestinal mucosa were measured by normal phase high-performance liquid chromatography (HPLC) after lipid extraction $(n=7)$. (b, c) Epithelial cells were recovered from fresh human gastric and intestinal tissue specimens by incubation with EDTA, and expression of genes involved in RA biosynthesis was analyzed by quantitative reverse transcriptase-PCR (qRT-PCR) using the random standard curve method. (b) Cytospins of hematoxylin and eosin (H\&E)-stained gastric and intestinal epithelial cells, original magnification $\times 20$. (c) Relative gene expression for $R D H 10$ and $A L D H 1 A 1$. Diamonds: individual samples; bars: mean; lines connect donor-matched samples; $n=6$. Statistical significance was determined using the Student's $t$-test.
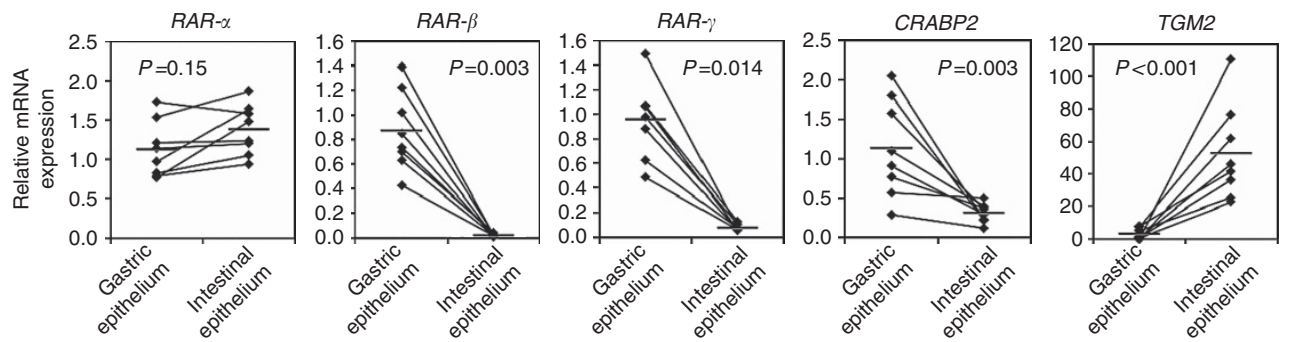

Figure 2 Increased expression of retinoic acid (RA) response genes in primary human gastric compared with intestinal epithelial cells. Epithelial cells were recovered from fresh human gastric and intestinal tissue specimens by incubation with EDTA, and gene expression of $R A R-\alpha, R A R-\beta, R A R-\gamma$, $C R A B P 2$, and TGM2 was analyzed by quantitative reverse transcriptase-PCR (qRT-PCR) using the random standard curve method. Diamonds: individual samples; bars: mean; lines connect donor-matched samples; $n=6-8$. Statistical significance was determined using the Student's $t$-test.

CRBP2 facilitates ROL uptake by intestinal epithelial cells and has been implicated in enhancing local retinoid concentrations. $^{19}$ Our experiments revealed that expression of CRBP2 was high in intestinal mucosa and epithelium but almost undetectable in gastric mucosa and epithelium $(P<0.001$; Supplementary Figure $\mathbf{1}$ online). Compared with small intestine, gastric expression of CRBP1 was modestly but significantly higher in complete mucosa, but not in isolated epithelial cells (Supplementary Figure 1). Thus, high local ROL retention by epithelial retinoid chaperones is not likely to be the cause for the high levels of ROL in gastric mucosa.

In the small intestine, free ROL can be either converted to RA or to retinyl esters, which are packaged in chylomicrons, transported to the liver through the lymphatics and then stored in stellate cells (Figure 3a). ${ }^{22}$ Analysis of human gastric and intestinal mucosa revealed significantly higher concentrations of retinyl esters in the small intestinal mucosa compared with the gastric mucosa (Figure 3b), and gene expression of the major enzyme involved in retinyl ester biosynthesis, lecithinROL-acyltransferase (LRAT), also was significantly higher in small intestinal epithelial cells than in gastric epithelial cells
(Figure 3c). These data indicate that ROL in gastric mucosa is not converted to retinyl esters, whereas efficient LRATdependent conversion of ROL to retinyl esters in the small intestine may decrease the amount of free ROL in this compartment.

\section{Gastric epithelial cells deliver RA to co-cultured antigen- presenting cells and drive antigen-presenting cell RA biosynthesis}

RA-dependent immune regulation in the small intestine involves the induction of RA biosynthesis gene expression in mucosal DCs by epithelial cell-derived RA through a positive feedback loop. ${ }^{6,10,11,23}$ To determine whether RA-producing gastric epithelial cells could similarly confer the ability to generate RA upon gastric DCs, we performed co-culture experiments with primary gastric epithelial cells and blood monocytes, which are precursor cells for certain DC subsets and which have a relatively low baseline ALDH activity. Gastric epithelial cells were pulsed with ROL $(2 \mu \mathrm{M})$ for $4-6 \mathrm{~h}$ to allow epithelial cell RA biosynthesis (Table 1), washed to remove free ROL, and blood monocytes were then added directly to the epithelial monolayers and harvested after overnight incubation 
a

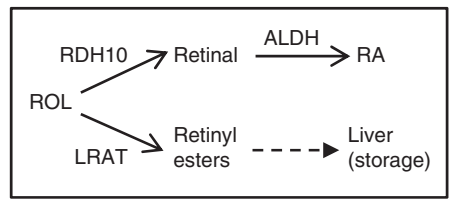

b

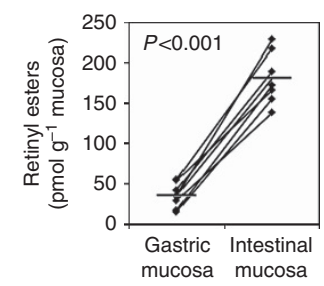

C

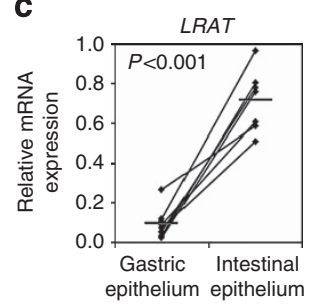

Figure 3 Small intestinal, but not gastric, epithelial cells are involved in biosynthesis of retinyl esters. (a) Alternative metabolic pathways for retinol usage by epithelial cells. (b) Tissue levels of retinyl esters in human gastric and small intestinal mucosa were measured by reverse phase high-performance liquid chromatography (HPLC) after lipid extraction $(n=7)$. (c) Freshly isolated human gastric and intestinal epithelial cells were analyzed for their expression of $L R A T$ by quantitative reverse transcriptase-PCR (qRT-PCR) using the standard curve method. Diamonds: individual samples; bars: mean; lines connect paired samples; $n=7$. Statistical significance was determined using the Student's $t$-test.

a

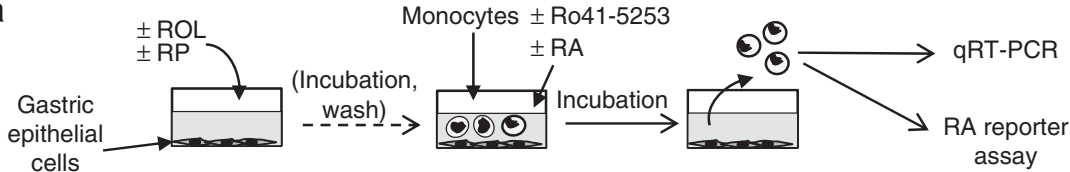

b

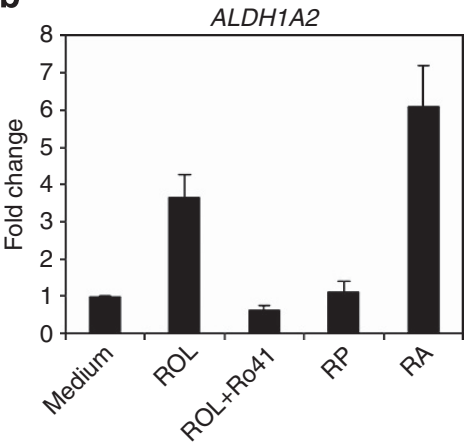

C

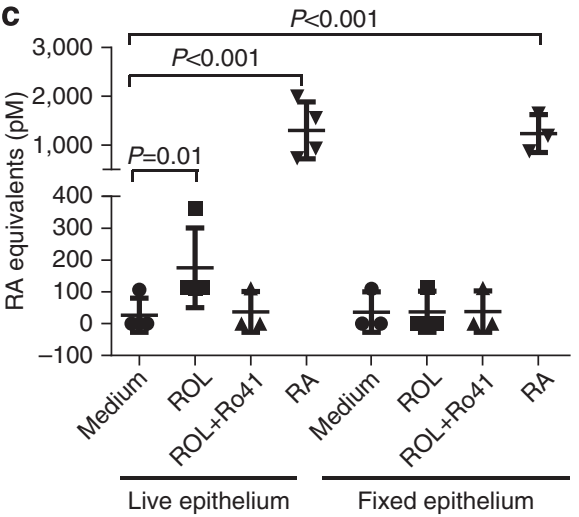

Figure 4 Retinol (ROL)-treated gastric epithelial cells induce retinoic acid (RA) biosynthesis in co-cultured antigen-presenting cells. (a) Experiment overview. (b) Monolayers of primary gastric epithelial cells were treated with ROL $(2 \mu \mathrm{M})$ or retinyl palmitate (RP; $2 \mu \mathrm{M})$ for $4-6 \mathrm{~h}$ and washed. Blood monocytes were then added at $1 \times 10^{6}$ per well, together with medium alone, the RA receptor (RAR) inhibitor Ro-41-5253 (Ro-41; $\left.1 \mu \mathrm{M}\right)$ or RA (50 nM). Monocytes were harvested after $16 \mathrm{~h}$, and gene expression of $A L D H 1 A 2$ in recovered monocytes was analyzed by quantitative reverse transcriptasePCR (qRT-PCR). ITGAX (CD11c) was used as a housekeeping gene. Data are from one representative experiment of four similar experiments. Mean \pm s.e.m. of duplicates. (c) Monolayers of primary gastric epithelial cells were kept in medium $(n=4)$ or fixed with $70 \%$ ethanol $(n=3)$ and then treated with ROL, ROL and Ro-41-5253, or RA. Blood monocytes were added at $1 \times 10^{6}$ per well for $6-8 \mathrm{~h}$ and then were harvested for analysis of RA production using the Sil-15 reporter cell line. Symbols: individual samples; bars: mean and s.d., $n=3-4$; Kruskal-Wallis test with Bonferroni correction.

(Figure 4a). Recovered monocytes were $>95 \%$ pure, as determined by fluorescence-activated cell sorting (FACS) analysis of CD45 and CD11c (data not shown). Monocytes co-cultured with ROL-pulsed epithelial cells showed a $>2$-fold increased expression of ALDH1A2 compared with monocytes co-cultured with untreated epithelial cells (Figure 4b; $n=4$, $P=0.02$, Kruskal-Wallis test with Bonferroni correction). In contrast, pretreatment of gastric epithelial cells with retinyl palmitate, a common dietary form of vitamin A that requires hydrolysis to ROL before it can enter the RA biosynthesis pathway, did not lead to increased $A L D H 1 A 2$ expression in cocultured monocytes (Figure $\mathbf{4 b}$ ). The induction of ALDH1A2 in monocytes co-cultured with ROL-treated epithelial cells was dependent on RA production, because addition of the RARreceptor antagonist Ro-41-5253 $(1 \mu \mathrm{M})$ to the co-cultures blocked monocyte ALDH1A2 expression. Moreover, exogenous addition of RA to the co-cultures also resulted in upregulation of monocyte $A L D H 1 A 2$ expression $(P<0.001)$. In contrast, monocyte expression of RDH10 and of $A L D H 1 A 1$, the epithelial cell-predominant ALDH isoform, was not significantly altered by any of the experimental conditions tested (data not shown).

To determine whether induction of monocyte ALDH1A2 expression by epithelial cell-derived RA results in monocyte RA biosynthesis, we used the RA-reporter cell line Sil-15. ${ }^{24}$ Monocytes were co-cultured for 6-8 h with gastric epithelial cells plus medium, ROL, ROL + Ro41-5253, or RA, harvested, and plated on top of the Sil-15 reporter cells for analysis of RA release (Figure 4a). Monocytes cultured in the presence of epithelial cells plus ROL, but not monocytes cultured in the 
a

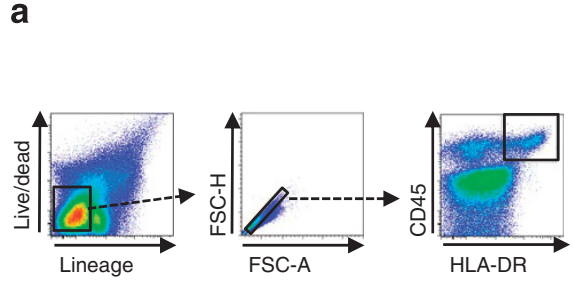

b
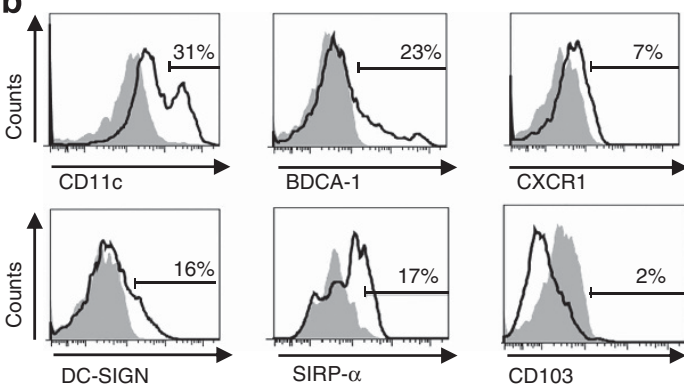

C

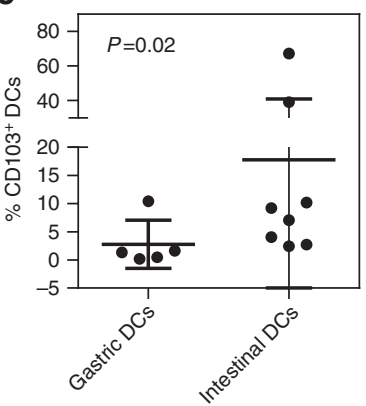

d

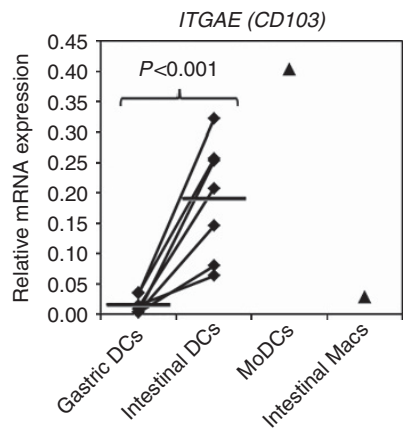

e

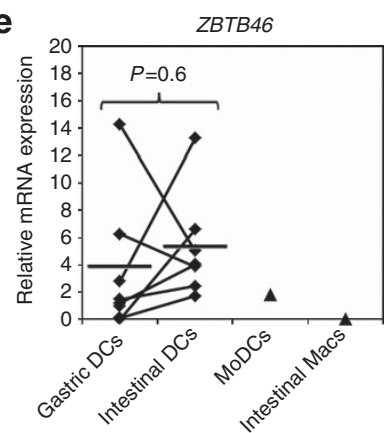

Figure 5 Gastric dendritic cells (DCs) lack expression of CD103. (a) Gating strategy for isolation of gastric and intestinal DCs. (b) Phenotype of isolated gastric DCs. Data are representative of $n=6-8$. (c) Intestinal DCs express higher levels of CD103 than gastric DCs. Diamonds: individual samples; bars: mean; $P=0.02$, Kruskal-Wallis test with Bonferroni correction; $n=6-8$. (d, e) Gastric DCs lack ITGAE (CD103) gene expression but express similar levels of ZBTB46. RNA was isolated from fluorescence-activated cell sorted (FACS) gastric and intestinal dendritic cells (live $\mathrm{HLA}^{-D R^{+}} / \mathrm{CD} 45^{+} /$/lineage cells), and expression of (d) ITGAE and (e) ZBTB46 was analyzed by quantitative reverse transcriptase-PCR (qRT-PCR). Monocyte-derived DCs (MoDCs; $n=1$ ) and elutriated intestinal macrophages (Macs, $n=1$ ) were analyzed for comparison. Diamonds: individual samples; bars: mean; lines connect paired samples; $n=7$. Statistical significance was determined using the Student's $t$-test.

presence of epithelial cells plus ROL + RAR-inhibitor, released significant amounts of RA (Figure 4c). In contrast, fixed epithelial cells provided with ROL were unable to drive monocyte RA release, indicating that conversion of ROL to RA by the epithelial cells is required to drive monocyte RA biosynthesis (Figure 4c). Monocyte RA release was also observed in monocytes treated directly with RA in the presence of epithelial cells, consistent with the elevated expression of ALDH1A2 in these cultures. However, RA release by RA-treated monocytes was higher than expected based on the gene expression data, thus, we cannot rule out that additional passive carry-over of RA by the monocytes occurred in these samples, in spite of extensive washing steps. Collectively, our results show that gastric epithelial cells can drive $A L D H 1 A 2$ expression and RA release in co-cultured monocytes through an RA-dependent pathway and support the notion that gastric epithelial cells provide RA to gastric DCs, thereby promoting DC RA biosynthesis.

\section{Gastric DCs lack CD103 expression, but synthesize RA as efficiently as intestinal DCs}

$\mathrm{CD}_{103}{ }^{+}$DCs, the major DC subset in murine small intestinal lamina propria, have an enhanced capacity to generate RA, ${ }^{6,25}$ but whether human gastric DCs express CD103 and synthesize RA is currently unknown. We have previously characterized human gastric DCs as HLA-DR ${ }^{\text {high }} / \mathrm{CD} 13^{\text {low }}$ cells that induce $\mathrm{CD}^{+}$T-cell interferon- $\gamma$ production but only weak proliferative responses. $^{2,26}$ Here, we show that freshly isolated human gastric DCs gated as live/lineage/HLA-DR ${ }^{\text {high }} / \mathrm{CD} 45^{+}$ singlet cells (Figure 5a) showed subset expression of CD11c $(46 \pm 11 \%, \quad n=6), \quad$ BDCA1 (CD1c, $28 \pm 9 \%), \quad$ DC-SIGN (CD209, $13 \pm 3 \%$ ), and SIRP- $\alpha$ (CD172a, $27 \pm 10 \%)$, but expressed only low levels of CXCR1 $(4 \pm 1 \%)$ and CD103 ( $3 \pm 1 \%$ ) (Figure $5 \mathbf{b}$ ). In contrast, similarly gated DCs from human small intestine expressed significantly higher levels of CD103 protein (Figures 5c; $P=0.02$, Kruskal-Wallis test with Bonferroni correction). The observed difference in CD103 expression between gastric and intestinal DCs was corroborated by quantitative reverse transcriptase-PCR analysis, which also revealed a significantly lower expression of ITGAE (CD103) mRNA in gastric compared with intestinal DCs (Figures 5d; $P=0.002$ ). Importantly, FACS-purified gastric and intestinal DCs expressed similar levels of the DC-specific transcription factor ZBTB46, confirming that both cell populations were $\mathrm{DCs}^{27}$ (Figure 5e). In comparison, control MoDCs displayed high expression of ITGAE and low expression of $Z B T B 46$, whereas intestinal macrophages showed low expression of both CD103 and ZBTB46.

We next determined whether human gastric DCs had the ability to synthesize RA, using the flow cytometry-based Aldefluor assay, which measures ALDH activity. ${ }^{28}$ Human gastric and intestinal DCs exhibited similar levels of ALDH activity (Figure 6a), whereas Aldefluor geometric mean fluorescence of blood monocytes was significantly lower. 


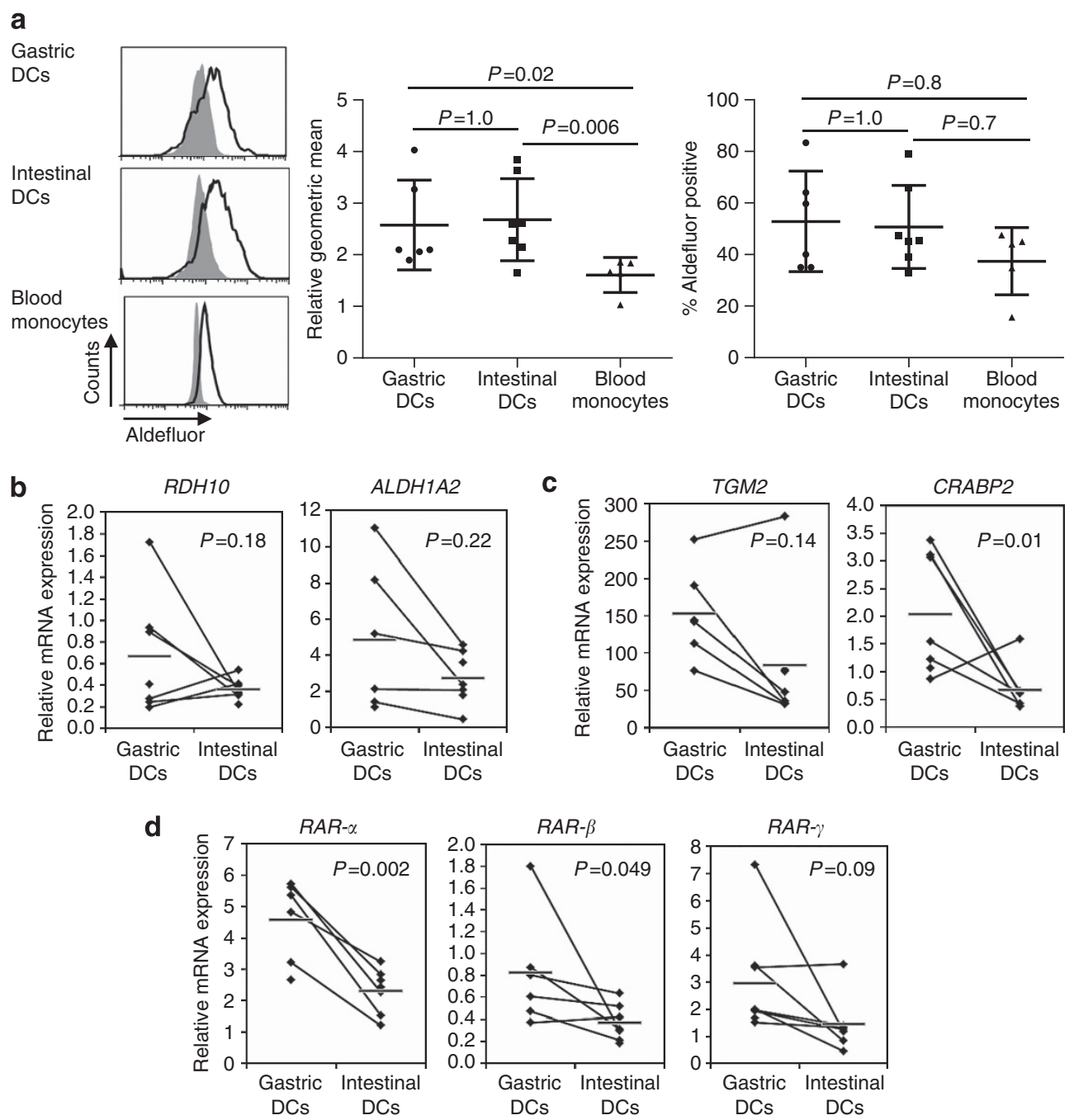

Figure 6 Gastric dendritic cell (DC) synthesize retinoic acid (RA) as efficiently as intestinal DCs. (a) ALDH activity of isolated gastric and intestinal DCs and blood monocytes was analyzed with the Aldefluor assay. Left panels: representative fluorescence-activated cell sorting (FACS) data; grey histograms: diethylaminobenzaldehyde (DEAB)-treated control cells, black outline: untreated samples. Middle panel: combined data from 5 to 7 experiments shown as geometric mean fluorescence (normalized to geomean of the DEAB-treated control); Right panel: combined data from 5 to 7 experiments shown as \% positive cells. (b, c) RNA was isolated from FACS-sorted gastric and intestinal dendritic cells (live $\mathrm{HLA}^{-D R^{\text {high }}} / \mathrm{CD} 45^{+} /$/lineage cells), and expression of (b) RA biosynthesis genes $R D H 10$ and $A L D H 1 A 2$, (c) RA response genes and TGM2 and CRABP2and (d) RA receptors RAR- $\alpha$, $R A R-\beta$, and $R A R-\gamma$ was analyzed by quantitative reverse transcriptase-PCR (qRT-PCR) using the random standard curve method. Diamonds: individual samples; bars: mean; lines connect paired samples; $n=5-7$. Statistical significance was determined using the Student's $t$-test.

Furthermore, FACS-purified gastric and intestinal DCs expressed similar levels of the RA biosynthesis genes RDH10, ALDH1A1, and ALDH1A2 (Figure 6b). Expression of RA response genes TGM2 and CRABP2 (Figure 6c) and the RA receptors $R A R-\alpha, R A R-\beta$, and $R A R-\gamma$ (Figure 6d) also was similar or higher in gastric DCs compared with intestinal DCs (Figure 6c), evidence of autocrine or paracrine RA signaling in gastric DCs. Taken together, these data suggest that gastric DCs are likely equivalent to small intestinal DCs in their ability to generate RA and provide RA to responsive T cells.

In the small intestine, RA-producing DCs direct $\mathrm{T}$ cells to the mucosa by inducing CCR9 and $\alpha 4 \beta 7 .{ }^{29}$ A previous report suggest that gastric T-cell homing is $\alpha 4 \beta 7$ dependent. ${ }^{30}$ To determine whether CCR9 may also have a role in gastric T-cell homing, we compared the expression of the cognate ligand for
CCR9, CCL25, in gastric and intestinal mucosa. Immunofluorescence and gene expression analysis showed that CCL25 was highly expressed in small intestinal mucosa, particularly on the basolateral side of intestinal crypts and around intestinal blood vessels, but absent from gastric mucosa (Supplementary Figure 2a and b). Therefore, we focused on $\alpha 4 \beta 7$ in our analysis of mucosal-homing molecule induction by gastric DCs. Interestingly, staphylococcal enterotoxin B-pulsed gastric DCs induced only low levels of $\alpha 4$ and $\beta 7$ co-expression on naive $\mathrm{CD} 4^{+} \mathrm{T}$ cells, whereas staphylococcal enterotoxin Bpulsed small intestinal DCs induced high levels of T-cell $\alpha 4 \beta 7$ expression (Supplementary Figure $\mathbf{2 c}$ and $\mathbf{d}$ ). This was paralleled by a low induction of proliferation by gastric DCs and a high induction of proliferation by intestinal DCs (data not shown), contrasting with our earlier published 
a Human stomach

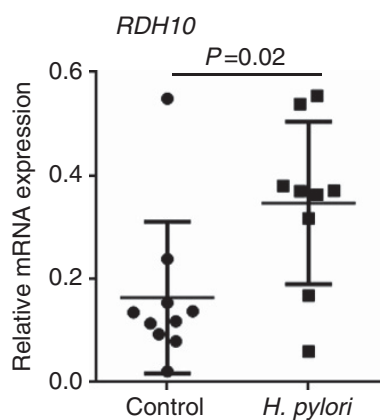

b

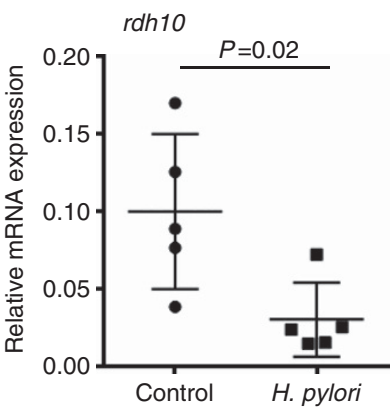

ALDH1A1

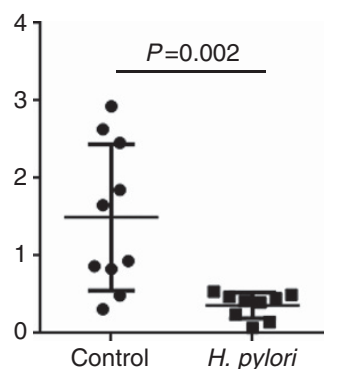

aldh1a1

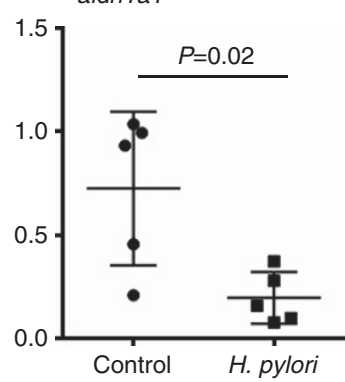

ALDH1A2

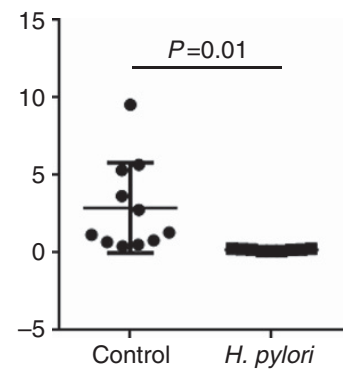

Figure 7 Gastric Helicobacter pylori infection interferes with retinoid metabolism. (a) RNA was isolated from human gastric biopsy specimens obtained from healthy or $\mathrm{H}$. pylori-infected subjects. Gene expression of $R D H 10, A L D H 1 A 1$, and $A L D H 1 A 2$ was determined by quantitative reverse transcriptase (qRT)-PCR using the random standard curve method, with data normalized to GAPDHexpression ( $n=9-11)$. (b) Six- to eight-week-old female C57/BL6 mice $(n=5)$ were infected with $\mathrm{H}$. pylori (SS1) for 2 months or were mock infected, stomachs were harvested, and gene expression of rdh 10, aldh1a1, and aldh1a2 was determined by qRT-PCR. Data were normalized to hprtexpression and analyzed using the $\Delta \Delta \mathrm{cT}$ method. (a, b) Dots and squares: individual samples; bars: mean and s.d. Statistical significance was determined using the Student's $t$-test.

report. ${ }^{2}$ Surprisingly, T-cell stimulation with anti-CD3/28beads also increased the expression of T-cell $\alpha 4 \beta 7$. Further investigations are necessary to elucidate how gastric DCs induce T-cell homing to the stomach.

\section{H. pylori infection disrupts RA biosynthesis in the gastric mucosa}

H. pylori infection causes altered gastric epithelial cell and gastric DC function and an infiltration of the gastric mucosa with $\mathrm{CD} 4{ }^{+}$T cells. $^{26,31}$ Infiltrating CD $4{ }^{+} \mathrm{T}$ cells in H. pyloriinfected adults are predominantly Th1 cells, ${ }^{32}$ and low $\mathrm{T}$ regulatory cell numbers in the $H$. pylori-infected gastric mucosa are associated with enhanced inflammation and increased frequency of peptic ulcer disease. ${ }^{33-35}$ As gastric DC-derived $\mathrm{RA}$ is likely involved in the generation of these effector and regulatory $\mathrm{T}$-cell populations in $H$. pylori infection, we investigated whether $H$. pylori infection modulates gastric RA biosynthesis. RA biosynthesis gene expression in gastric mucosal biopsies obtained from $H$. pylori-infected subjects and healthy controls was analyzed by quantitative reverse transcriptase-PCR. Our experiments revealed that $H$. pylori infection was associated with a significantly increased gene expression of Rdh10 and a significantly decreased expression of Aldh1a1 and Aldh1a2 (Figure 7a). We confirmed these observations in a mouse model of chronic H. pylori infection (Figure 7b). C57/ BL6 mice were gavaged with $H$. pylori strain SS1 to establish gastric infection, and, 2 months later, gastric tissue was analyzed for RA biosynthesis gene expression. Similar to our findings using human samples, $H$. pylori infection in mice was associated with a significant decrease in the expression of aldh1a1 and aldh1a2 (Figure 7b). Moreover, $H$. pylori infection in mice also caused a significant decrease in $r d h 10$ expression. These data indicate that chronic $H$. pylori infection disrupts RA biosynthesis in the gastric mucosa.

\section{DISCUSSION}

The high prevalence of chronic gastritis as a result of $H$. pylori infection and the often lethal outcome of gastric adenocarcinoma that may develop as a consequence of chronic $H$. pylori gastritis highlight the importance of studying the gastric mucosa as a unique immunological compartment. Here, we investigated whether RA may contribute to immune regulation in human gastric mucosa. Our data provide evidence that both gastric epithelial cells and gastric DCs generate RA under steady-state conditions, similar to small intestinal epithelial cells and DCs. ${ }^{5,36}$ Specifically, we show that (a) gastric mucosa contains ROL, the precursor molecule for RA, thus allowing RA biosynthesis; (b) primary human gastric epithelial cells have the ability to generate RA and confer the ability to generate RA to co-cultured antigen-presenting cells; and (c) gastric DCs have a similar capacity for RA biosynthesis as intestinal DCs, although, surprisingly, 
gastric DCs lack CD103 expression. These data support the hypothesis that RA signaling contributes to immune homeostasis in human gastric mucosa.

In addition to the homeostatic and tolerogenic effects of RA in the intestinal immune system, RA has key regulatory functions for cell development, proliferation, survival and metabolism and for tissue morphogenesis. ${ }^{12,37,38}$ Therefore, RA metabolism and tissue concentrations are tightly controlled through auto- and paracrine positive and negative feedback mechanisms. ${ }^{15,37,39}$ Genes that are direct regulatory targets of RA include RAR- $\alpha, R A R-\beta, R A R-\gamma, C R A B P 2$, and $A L D H 1 A 2$, where binding of RA to RA receptor heterodimers allows interaction of the RA receptor complex with DNA response elements of the target genes. ${ }^{11,15,40}$ RA biosynthesis by small intestinal DCs is crucial for the induction of gut-homing properties and Foxp 3 expression in responder T cells, ${ }^{29,41,42}$ and RA biosynthesis capacity of mucosal DCs is, in turn, dependent on the presence of RA, because small intestinal DCs from vitamin A (ROL)-deficient mice have significantly decreased ALDH expression and activity. ${ }^{13,28}$ In our study, increased expression of the RA biosynthesis genes RDH10 and ALDH1A1 in gastric compared with intestinal epithelial cells was paralleled by a higher expression of the RA response genes $R A R-\beta, R A R-\gamma$, and $C R A B P 2$, indicating that the gastric epithelial cells were actively generating RA. Importantly, RA released by ROL-treated gastric epithelial cells significantly upregulated ALDH1A2 expression and RA production in cocultured monocytes through an RA-dependent mechanism, evidence for a positive paracrine feedback loop.

Data from previous reports ${ }^{10,43}$ point to a crucial role for epithelial cells in imprinting DCs with RA biosynthesis capacity. Thus, direct co-culture of murine bone marrowderived DCs with MODE-K cells and $\mathrm{IC}_{\mathrm{C} 12}$ cells, two murine small intestinal epithelial cell lines, resulted in an increased DC expression of ALDH1A2 and both ALDH1A1 and ALDH1A2, respectively. Our report is the first to demonstrate that primary human epithelial cells can confer RA-metabolizing activity upon primary human antigen-presenting cells and to show that the mechanism proposed for the imprinting of small intestinal DCs with RA-biosynthesis capacity also may apply to gastric DCs. Notably, several factors other than RA may drive $A L D H 1 A 2$ expression in antigen-presenting cells, including Toll-like receptor engagement, ${ }^{44}$ peroxisome proliferatoractivated receptor- $\gamma$ ligands, ${ }^{9,45}$ granulocyte-macrophage colony-stimulating factor (GM-CSF), and other cytokines. ${ }^{11,28}$ In our study, induction of monocyte ALDH1A2 expression and RA production were dependent on RA signaling, because altered expression was not detected in the presence of the RAR- $\alpha$ inhibitor Ro41-5253. Interestingly, a recent study showed that, in murine DCs, GM-CSF may potentiate RAinduced Aldh1a2 gene expression through co-operative binding of GM-CSF-activated Sp1 and the RAR/RXR complex to the Aldh1a2 promoter. $^{11}$ As gastric epithelial cells have been reported to secrete GM-CSF, ${ }^{46}$ this mechanism may have contributed to the induction of ALDH1A2 expression and RA production in our experiments.
The small intestine was previously considered a privileged site for RA biosynthesis, because tissue levels of ROL are higher in small intestine than in most other tissues including spleen and colon. ${ }^{13}$ In this context, small intestinal epithelial cells are thought to have access to luminal ROL from dietary sources and bile $^{6}$ and express high levels of CRBP2, which may enhance luminal ROL uptake. ${ }^{19}$ Therefore, we were surprised that gastric mucosa contained significantly higher levels of ROL than small intestinal mucosa. Indeed, gastric mucosa also showed higher epithelial cell expression of RA biosynthesis genes and higher DC and epithelial cell expression of RA response genes, indicative of higher RA levels in stomach compared with small intestine. However, the source of this high ROL concentration in human gastric mucosa remains unclear. First, the gastric mucosa does not have direct access to free ROL from the diet, because dietary vitamin A sources, that is, retinyl esters or carotenes, require conversion to free ROL or retinal by small intestinal brush border enzymes or pancreatic enzymes that are not present in the stomach. ${ }^{47}$ Indeed, in our co-culture experiments, gastric epithelial cells were unable to utilize the retinyl ester retinyl palmitate, but required free ROL in order to drive RA biosynthesis in co-cultured monocytes. Second, CRBP2, which may increase local ROL concentrations, ${ }^{19}$ is not expressed by gastric epithelial cells, as we have shown. However, our study revealed a significant difference in retinyl ester biosynthesis between gastric and small intestinal mucosa in that ROL is metabolized to retinyl esters by LRAT for subsequent liver transport and storage in the small intestine but not the stomach, thereby reducing ROL levels and the local availability of ROL for RA biosynthesis in the intestinal tissue. This difference between gastric and intestinal epithelial cell ROL metabolism may partly account for the higher levels of ROL observed in gastric compared with intestinal mucosa. Notably, stromal cells also may be involved in retinoid metabolism. ${ }^{48}$ Our analyses did reveal that total gastric mucosa, but not gastric epithelial cells, expressed high levels of the ROL chaperone CRBP1. Conceivably, CRBP1-expressing gastric stromal cells may elevate local ROL levels by sequestration of serum-derived ROL.

Another unexpected finding in our study was the absence of $\mathrm{CD} 103 /$ integrin $\alpha \mathrm{E}$ protein and mRNA expression in gastric DCs, in spite of the similar ALDH activity levels and RA biosynthesis gene expression in donor-matched gastric and small intestinal DCs. In mouse small intestinal lamina propria, the majority of DCs express CD103, and the $\mathrm{CD} 103^{+}$DCs express higher levels of aldh1a2 than $\mathrm{CD}_{103^{-}}$DCs. ${ }^{5,42}$ In our hands, although ITGAE mRNA levels were high, surface expression of CD103 on human small intestinal DCs was variable and considerably lower than that reported by Watchmaker et al. ${ }^{49} \mathrm{CD} 103$ expression is induced by transforming growth factor- $\beta,{ }^{50}$ raising the possibility that the significantly lower expression of $\mathrm{CD} 103$ by gastric DCs compared with small intestinal DCs is due to the lower concentration of transforming growth factor- $\beta$ that we reported for gastric lamina propria compared with intestinal lamina propria. ${ }^{2}$ Notably, CD103 ${ }^{-}$ DCs in murine skin draining lymph nodes also had a high RA 
biosynthesis activity ${ }^{51}$ and, in human intestinal DCs, both $\mathrm{CD}_{103^{-}}$SIRP $\alpha^{+}$DCs and $\mathrm{CD}_{103}{ }^{+}$SIRP $\alpha^{+}$had high levels of ALDH activity, whereas ALDH activity in $\mathrm{CD}_{103}{ }^{+} \mathrm{SIRP}^{-}$ DCs was significantly lower. ${ }^{49}$ Thus, consistent with our observations, expression of CD103 does not seem to be a requirement for RA biosynthesis by DCs.

Our study has yielded novel data indicating that gastric epithelial cells and DCs generate RA in human gastric mucosa, thereby potentially contributing to the generation of tolerogenic responses to gastric commensals. However, $H$. pylori infection in human adults does not lead to tolerance, with only few FoxP $3^{+}$T regulatory cells present in the H. pylori-infected gastric mucosa, as we have shown. ${ }^{33}$ To explain these findings, our data suggest that RA biosynthesis may be significantly disrupted in the $H$. pylori-infected stomach, reflected in the decreased expression of ALDH1A1 and ALDH1A2 in both human tissue samples from subjects naturally infected with $H$. pylori and in a mouse model of chronic $H$. pylori infection. Consistent with our observations, Matsumoto et al. ${ }^{12}$ previously determined that RA formation decreased with increased levels of gastric inflammation. Potential mechanisms for $H$. pylori-induced inhibition of RA biosynthesis include inhibition of RA biosynthesis gene expression by $H$. pylori or inflammatory mediators, or reduced dietary vitamin A absorption because of altered gastrointestinal physiology in chronic $H$. pylori infection, as previously suggested. ${ }^{52}$ Disruption of RA pathways in the H. pylori-infected gastric mucosa may contribute to disease pathogenesis through at least two potential mechanisms. Lack of RA biosynthesis by DCs could lead to decreased induction of Foxp $3^{+} \mathrm{T}$ regulatory cells, thereby allowing increased pro-inflammatory responses and enhanced inflammation. Alternatively, lack of RA could lead to reduced recruitment of protective Th1 cells to the infected mucosa, thereby promoting chronic infection. In support of this hypothesis, H. pylori-infected children who lacked vitamin A had higher bacterial counts than children with normal vitamin A intake. ${ }^{53}$ Moreover, disrupted RA signaling in gastric epithelial cells could contribute to the development of gastric adenocarcinoma, because RA restricts cell cycle progression and proliferation and promotes cell differentiation, important antitumor mechanisms. ${ }^{38}$ Disruption of retinoid signaling including reduced ALDH activity is a common finding in many types of cancer. ${ }^{38}$ On the other hand, antitumor effects of alltrans RA treatment on human gastric cancer cells have been demonstrated both in vitro and in vivo. ${ }^{54,55}$

One crucial question that is the subject of ongoing investigations in our laboratory is whether RA-producing gastric DCs can direct lymphocyte homing to the gastric lamina propria. CCL25, the cognate ligand for CCR9, was not expressed in gastric mucosa, and our preliminary results did not support the hypothesis that gastric DCs induce T-cell $\alpha 4 \beta 7$ expression. Thus, the mechanisms by which gastric DCs may induce $\mathrm{T}$-cell homing to the gastric mucosa remain to be elucidated.

In summary, we show that gastric epithelial cells are more effective than small intestinal epithelial cells in the ability to generate RA. Gastric DCs similarly are able to generate RA, likely due to induction of DC ALDH1A2 expression by epithelial cell-derived RA. These results suggest that RA biosynthesis by gastric epithelial cells and DCs may contribute to gastric homeostasis under steady-state conditions, however, H. pylori infection may disrupt RA-dependent mechanisms that support gastric homeostasis.

\section{METHODS}

Cells and tissues. Gastric tissue specimens from corpus and antrum and small intestinal tissue specimens from proximal jejunum were obtained with Institutional Review Board (IRB) approval and informed consent from non- $H$. pylori-infected adult subjects undergoing elective gastric bypass for obesity or diagnostic esophagogastro-duodenoscopy at the University of Alabama at Birmingham (40 donors). One surgical sample (approximately $1 \mathrm{~g}$ of gastric mucosa) or 10-20 biopsies were obtained from each donor; data points in the figures represent cells derived from one subject. Additional gastric biopsy specimens from $H$. pylori-infected and non-infected subjects were obtained with local IRB approval from adult subjects with abdominal symptoms residing in Santiago, Chile (20 donors). H. pylori status was determined by rapid urease test and microscopic evaluation, and a study subject was judged colonized with $H$. pylori if one or both tests were positive for the bacteria. Exclusion criteria included (a) use of antibiotics, antacid, $\mathrm{H}_{2}$-blocker, proton-pump inhibitor, bismuth compound, non-steroidal anti-inflammatory drug, or immunosuppressive agent during the 2 weeks before endoscopy; and (b) stool examination positive for ova or parasites.

Gastric epithelial cell cultures were established as previously described. ${ }^{56,57}$ Briefly, tissue was minced with a scalpel blade and digested for $1 \mathrm{~h}$ at $37^{\circ} \mathrm{C}, 200$ r.p.m., in RPMI1640 with collagenase $(0.5$ FALGPA units $\mathrm{ml}^{-1}$; Sigma, St Louis, MO), DNAse $\left(0.2 \mathrm{mg} \mathrm{ml}^{-1}\right.$; Sigma) and bovine serum albumin (0.3\%; Fisher, Fair Lawn, NJ). Recovered cells were suspended in F12K medium containing $10 \%$ fetal bovine serum, amphotericin $\left(125 \mathrm{ng} \mathrm{m}^{-1}\right)$, penicillin $\left(100 \mathrm{U} \mathrm{ml}^{-1}\right)$, streptomycin $\left(100 \mu \mathrm{g} \mathrm{ml}^{-1}\right)$, and gentamycin $\left(50 \mu \mathrm{g} \mathrm{ml}^{-1}\right)$, plated on collagen-I-coated plates (Biocoat, Becton Dickinson, San Jose, CA), and non-adherent cells were removed after $18 \mathrm{~h}$ of culture $\left(37^{\circ} \mathrm{C} ; 5 \%\right.$ $\mathrm{CO}_{2}$ ). Cultures were maintained for up to 5 days.

To obtain gastric and small intestinal epithelial cells for PCR analysis, tissue from bypass patients was dissected to remove the serosa and muscularis layers and then washed twice for $20 \mathrm{~min}$ at $37^{\circ} \mathrm{C}, 200$ r.p.m., in Hank's balanced salt solution with dithiothreitol $\left(0.2 \mathrm{mg} \mathrm{ml}^{-1}\right.$, Sigma) to remove adherent mucus. Epithelial cells then were isolated by incubation ( $30 \mathrm{~min}, 37^{\circ} \mathrm{C}, 200$ r.p.m.) in Hank's balanced salt solution/ dithiothreitol supplemented with EDTA $(1.25 \mathrm{mM})$.

To obtain gastric and intestinal DCs (DCs), mucosal tissue was subjected to three rounds of EDTA treatment and then digested with collagenase solution, as described previously. ${ }^{26}$ Gastric and intestinal DCs were pre-enriched for HLA-DR ${ }^{+}$cells by MACS (Miltenyi Biotec, Auburn, CA), and viable (propidiumiodide-negative) $\mathrm{CD} 45^{\mathrm{pos}} /$ lineage ${ }^{\text {neg }} / \mathrm{HLA}-\mathrm{DR}^{\text {high }}$ DCs were purified by FACS sorting on a FACSAria II sorter (Becton Dickinson).

Animal studies. Six- to eight-week-old female C57/BL6 mice (Jackson Laboratory, Bar Harbor, ME) housed in the animal maintenance facility at the University of Michigan Health System were orally gavaged with $H$. pylori (strain SS1, $10^{9}$ bacteria per dose) three times over 1 week, as described previously. ${ }^{58}$ After 2 months, the mice were killed, and stomachs were harvested and processed for RNA isolation. All animal experiments were approved by the University Committee on Use and Care of Animals at the University of Michigan.

Quantitative reverse transcriptase-PCR analysis. For gene expression analysis in human samples, RNA was isolated from epithelial cells or dissected mucosa using the RNeasy Minikit (Qiagen, 
Valencia, CA). Alternatively, to obtain RNA from gastric and intestinal DCs, cells were directly sorted into Trizol LS (Invitrogen, Carlsbad, CA), and RNA was obtained using the Direct-zol RNA Mini Prep Kit (Zymo Research, Irvine, CA). Complementary DNA was generated with iScript Reverse Transcriptase (Bio-Rad, Hercules, CA). ALDH1A1 (Hs00180254_m1), ALDH1A2 (Hs00180254_m1), ITGAX (CD11c, Hs01015064_m1), ITGAE (CD103, Hs01025372_m1), CCL25 (Hs_00608373_m1), CRBP2 (Hs00188160_m1), RAR- $\alpha$ (Hs00940446_m1), TGM2 (Hs00190278_m1), ZBTB46 (Hs01008168_m1), 18s rRNA (ref. seq. X03205.1), and GAPDH (ref. seq. NM_002046.3) were amplified for 40 cycles $\left(15 \mathrm{~s} 95^{\circ} \mathrm{C}, 60 \mathrm{~s} 60^{\circ} \mathrm{C}\right)$ in $25 \mu \mathrm{l}$ reactions containing TaqMan Universal PCR Master Mix and appropriate primer probe sets, all from Applied Biosystems, Foster City, CA. RDH10, RAR- $\beta, C R B P 1, C R A B P 2$, and $L R A T$ were amplified for 45 cycles $\left(15 \mathrm{~s} 94{ }^{\circ} \mathrm{C}, 15 \mathrm{~s} 62^{\circ} \mathrm{C}, 15 \mathrm{~s} 72^{\circ} \mathrm{C}\right)$ in $25 \mu \mathrm{l}$ reactions containing SYBR Green ER qPCR Super Mix (Life Technologies, Carlsbad, CA). Sequences of primers used for SYBR green reactions are available upon request. Real-time PCR reactions were run on a Chromo4 PCR system (Bio-Rad), and analyzed with Opticon Monitor software, version 3.1 (Bio-Rad). Gene expression was calculated using the standard curve method or the Pfaffl method, ${ }^{59}$ with data normalized to the geometric mean of GAPDH and $18 \mathrm{~s} r R N A$, unless stated otherwise. ITGAX gene expression was used to normalize monocyte gene expression in epithelial cell-monocyte co-culture experiments in order to exclude contaminating epithelial cells from the analysis; CD11c expression was stable across different treatments.

Gene expression analysis in murine gastric samples was performed with SYBR Green as described previously, ${ }^{58}$ with the house keeping gene Hypoxanthine-guanine phosphoribosyltransferase (HPRT) used as an internal control and gene expression calculated using the $\Delta \Delta \mathrm{cT}$ method. Primer sequences are available upon request.

Retinoid detection by HPLC. Tissue samples and culture supernatants for retinoid analysis were prepared under red light, wrapped in aluminum foil, frozen on dry ice, and stored at $-80^{\circ} \mathrm{C}$ until further processing. Retinoids were extracted from cell culture medium or tissue homogenates as described before. ${ }^{60}$ The organic phase was evaporated under a stream of nitrogen. Normal or reverse phase HPLC were used as indicated in the respective figure legends. For normal phase HPLC analysis, the dry residue was dissolved in a mobile phase consisting of hexane/ethyl acetate/acetic acid (95:4.975:0.025, v/v/v). Samples were separated on Spherisorb S3W column $(4.6 \mathrm{~mm} \times 100 \mathrm{~mm})$ (Waters, Milford, MA) at a flow rate of $0.7 \mathrm{ml} \mathrm{min}^{-1}$ using Waters Alliance 2695 HPLC system equipped with a Waters 2996 photodiode array. For reverse phase HPLC analysis, samples were dissolved in acetonitrile: dichloromethane $(70: 30, \mathrm{v} / \mathrm{v})$ and separated on a SUPELCOSIL Suplex pKb-100 column (SigmaAldrich, St. Louis, MO) with a mobile phase consisting of a gradient of solvents A (acetonitrile: $2 \%$ ammonium acetate: glacial acetic acid: methanol as 79:16:3:2) and B (acetonitrile: dichloromethane as 90:10) as follows: $0-24 \min 100 \%$ A, 25-54 min $100 \%$ B, 55-60 min $100 \%$ B. Peaks were identified by comparison to retention times of retinoid standards and evaluation of wavelength maxima and quantified by comparing their peak areas with a calibration curve constructed from peak areas of a series of standards.

Retinoid treatment of gastric epithelial cells and co-culture experiments. ROL, RA, and RP were obtained from Sigma, and stock solutions were maintained in $100 \%$ ethanol (ROL), dimethylsulphoxide (RA), or tetrahydrofurane (retinyl palmitate), respectively, at $-80^{\circ} \mathrm{C}$. All reagents were pre-diluted in fetal bovine serum and vortexed vigorously before addition to cell culture media. Integrity and concentration of the reagents were checked periodically by comparing UV-Vis absorption spectra, which were obtained using a Nanodrop II spectrophotometer (Thermo Scientific, Waltham, MA), to reference spectra. All retinoid treatments were performed under red light illumination to avoid disintegration of the reagents. To analyze RA synthesis by gastric epithelial cells, 3-day-old gastric epithelial cell monolayers were treated with $2 \mu \mathrm{M}$ ROL overnight (16h). RA, ROL, and retinal concentrations in cell-free culture supernatants were analyzed by normal phase HPLC as described above. Co-culture experiments of primary human gastric epithelial cells and blood monocytes were performed to investigate the influence of epithelial cell-derived RA on antigen-presenting cell RA biosynthesis. Blood monocytes were isolated from peripheral blood mononuclear cells using anti-CD14 MACS beads (Miltenyi Biotec). Live gastric epithelial cell monolayers or dead control monolayers prepared by 30 -s fixation with $70 \%$ ethanol were treated with $2 \mu \mathrm{M}$ of ROL or RP or were left untreated. Monocytes were added at $1 \times 10^{6}$ per well, either immediately or after 4- to 6-h pretreatment of the epithelial cells with retinoids. Control co-culture wells contained RA $(50 \mathrm{nM})$ or the RA receptor inhibitor Ro41-5253 (1 $\mu \mathrm{M}$, Enzo, Life Sciences, Farmingdale, $\mathrm{NY})$. After co-culture, monocytes were recovered by vigorous pipetting and processed for further analysis.

RA bioassay. The Sil-15 cell line, ${ }^{24}$ kindly provided by Dr Michael Wagner, SUNY Downstate Medical Center, Brooklyn, NY, was used to assess RA production by monocytes recovered from epithelial cell coculture experiments. Sil-15 cells were grown on gelatin-coated 96-well plates (BD Labware, Bedford, MA) in Dulbecco's modified Eagle's medium supplemented with $20 \%$ fetal bovine serum and $1 \%$ G418 (Mediatech, Manassas, VA). Cellular populations to be tested were added at 100,000 per well to confluent monolayers of Sil-15 cells. After overnight incubation, supernatants were removed, and Sil-15 cells were lysed by three freeze-thaw cycles in phosphate-buffered saline. $\beta$-Galactosidase activity in Sil-15 lysates was then determined using $\mathrm{X}-\mathrm{Gal}\left(1 \mathrm{mg} \mathrm{ml}^{-1}\right.$; Thermo Scientific) in developer solution made of $5 \mathrm{mM} \mathrm{K}_{3}\left[\mathrm{Fe}(\mathrm{CN})_{6}\right], 5 \mathrm{mM} \mathrm{K}_{4}\left[\mathrm{Fe}(\mathrm{CN})_{6}\right]$, and $2 \mathrm{mM} \mathrm{MgCl}_{2}$ in phosphatebuffered saline, and color development was measured at $630 \mathrm{~nm}$. RA production was calculated as RA equivalents based on a standard curve generated with known amounts of RA (detection range $50 \mathrm{pM}-100 \mathrm{nM})$.

DC-T-cell co-cultures. DC-T-cell co-cultures were established using FACS-purified gastric and intestinal DCs that were pulsed with staphylococcal enterotoxin B $\left(1 \mu \mathrm{g} \mathrm{ml}^{-1}\right.$, Toxin Technology, Sarasota, $\mathrm{FL})$ and autologous naive $\mathrm{CD} 4^{+} \mathrm{T}$ cells, as described previously. ${ }^{2}$ $\mathrm{T}$-cell proliferation was determined using the CFSE dilution assay.

Immunofluorescence and flow cytometry. Antibodies directed against the following human surface proteins were used: HLA-DR (L243), CD11c (B-ly6), DC-SIGN (DCN46), CXCR1 (5A12), B7 (FIB504), $\alpha 4$ (9F10), cytokeratin (CAM5.2), CD45 (2D1, all from Becton Dickinson); BDCA-1/CD1c (L161), SIRP- $\alpha$ (SE5A5, both from Biolegend, San Diego, CA); CCL25 (rabbit polyclonal, from AbD Serotec, Raleigh, NC); and CD103 (B-Ly7, eBioscience, San Diego, CA). Our lineage cocktail contained antibodies to CD3, CD14, CD19, and CD20 (all from Becton Dickinson). A LIVE/DEAD yellow dye (Life Technologies) or propidiumiodide were used to exclude dead cell populations. The capacity of live cells to convert retinaldehyde to RA was measured using the flow cytometry-based Aldefluor assay according to the manufacturer's protocol (Stemcell Technologies, Vancouver, BC, Canada). The Aldefluor assay uses a fluorescent nontoxic aminoacetaldehyde, which freely diffuses into intact and viable cells and is converted by ALDH into an aminoacetate that is retained inside the cells. An LSRII flow cytometer (Becton Dickinson) and FlowJo 7.6.5 software (TreeStar, Ashland, OR) were used for analysis. Immunofluorescence staining of frozen gastric and intestinal sections was performed as described previously. ${ }^{26}$

Statistical analysis. Data were analyzed using Microsoft Excel 2003 and Analyse-it for Excel, version 1.73 (Leeds, UK), or GraphPad Prism 6.04 (La Jolla, CA). Results are presented as mean \pm s.e.m. Differences between values were analyzed for statistical significance by the twotailed Student's $t$-test, unless stated otherwise. Differences were considered significant at $P<0.05$. 
SUPPLEMENTARY MATERIAL is linked to the online version of the paper at http://www.nature.com/mi

\section{ACKNOWLEDGMENTS}

Our sincerest thanks to Dr Natalia Kedishvili and Dr Olga Belyaeva, Department of Biochemistry and Molecular Genetics, University of Alabama at Birmingham, for performing HPLC analyses, providing critical feedback on our study, and for sharing their knowledge on retinoid metabolism, function, and detection with us. We would also like to thank Marion Spell for performing FACSAria cell sorts, Dr Michael Wagner for providing the Sil-15 RA reporter cells, and Dr Heidi J. Nick for helpful discussions. Funding for our study was provided by the National Institutes of Health grants: DK-54495 (PDS); DK-084063 (PDS); AI-083539 (LES); DK097144 (DB); DK-087708 (JYK); the UAB Autoimmunity, Immunology and Transplantation Steering Committee Pilot Program (DB); the UAB CCTS Pilot Program UL1 TR000165 (DB); the Broad Medical Research Program of the Broad Foundation (LES); the Crohn's and Colitis Foundation of American (LES) and the Research Service of the Veterans Administration (PDS). Services from the Analytic and Preparative Cytometry Facility (P30 AR48311) and the DDRDC Human Cell/Tissue Core (DK-64400) were used for our study.

\section{DISCLOSURE}

The authors declared no conflict of interest.

c 2015 Society for Mucosal Immunology

\section{REFERENCES}

1. Atherton, J.C. \& Blaser, M.J. Coadaptation of Helicobacter pylori and humans: ancient history, modern implications. J. Clin. Invest. 119, 24752487 (2009)

2. Bimczok, D., Grams, J.M., Stahl, R.D., Waites, K.B., Smythies, L.E. \& Smith, P.D. Stromal regulation of human gastric dendritic cells restricts the Th1 response to Helicobacter pylori. Gastroenterology 141, 929-938 (2011).

3. Yang, I., Nell, S. \& Suerbaum, S. Survival in hostile territory: the microbiota of the stomach. FEMS Microbiol. Rev. 37, 736-761 (2013).

4. Bik, E.M. et al. Molecular analysis of the bacterial microbiota in the human stomach. Proc. Natl. Acad. Sci. USA 103, 732-737 (2006).

5. Iwata, M. Retinoic acid production by intestinal dendritic cells and its role in T-cell trafficking. Semin. Immunol. 21, 8-13 (2009).

6. Agace, W.W. \& Persson, E.K. How vitamin A metabolizing dendritic cells are generated in the gut mucosa. Trends Immunol. 33, 42-48 (2012).

7. Pino-Lagos, K., Benson, M.J. \& Noelle, R.J. Retinoic acid in the immune system. Ann. N.Y. Acad. Sci 1143, 170-187 (2008).

8. del Rio, M.L., Bernhardt, G., Rodriguez-Barbosa, J.I. \& Forster, R. Development and functional specialization of CD103 + dendritic cells. Immunol. Rev. 234, 268-281 (2010).

9. Gyongyosi, A. et al. RDH10, RALDH2, and CRABP2 are required components of PPARgamma-directed ATRA synthesis and signaling in human dendritic cells. J. Lipid Res. 54, 2458-2474 (2013).

10. Edele, F. et al. Cutting edge: instructive role of peripheral tissue cells in the imprinting of Tcell homing receptor patterns. J. Immunol. 181, 3745-3749 (2008).

11. Ohoka, Y., Yokota-Nakatsuma, A., Maeda, N., Takeuchi, H. \& Iwata, M. Retinoic acid and GM-CSF coordinately induce retinal dehydrogenase 2 (RALDH2) expression through cooperation between the RAR/RXR complex and Sp1 in dendritic cells. PLoS One 9, e96512 (2014).

12. Matsumoto, M., Yokoyama, H., Suzuki, H., Shiraishi-Yokoyama, H. \& Hibi, T. Retinoic acid formation from retinol in the human gastric mucosa: role of class IV alcohol dehydrogenase and its relevance to morphological changes. Am. J. Physiol. Gastrointest. Liver Physiol. 289, G429-G433 (2005).

13. Jaensson-Gyllenback, E. et al. Bile retinoids imprint intestinal CD103+ dendritic cells with the ability to generate gut-tropic T cells. Mucosal Immunol 4, 438-447 (2011).

14. Lee, S.A., Belyaeva, O.V., Wu, L. \& Kedishvili, N.Y. Retinol dehydrogenase 10 but not retinol/sterol dehydrogenase(s) regulates the expression of retinoic acid-responsive genes in human transgenic skin raft culture. J. Biol. Chem. 286, 13550-13560 (2011).
15. Balmer, J.E. \& Blomhoff, R. Gene expression regulation by retinoic acid. J. Lipid Res. 43, 1773-1808 (2002).

16. Yan, Z.H., Noonan, S., Nagy, L., Davies, P.J. \& Stein, J.P. Retinoic acid induction of the tissue transglutaminase promoter is mediated by a novel response element. Mol. Cell Endocrinol. 120, 203-212 (1996).

17. Chiocca, E.A., Davies, P.J. \& Stein, J.P. The molecular basis of retinoic acid action. Transcriptional regulation of tissue transglutaminase gene expression in macrophages. J. Biol. Chem. 263, 11584-11589 (1988).

18. Gundemir, S., Colak, G., Tucholski, J. \& Johnson, G.V. Transglutaminase 2: a molecular Swiss army knife. Biochim. Biophys. Acta. 1823, 406-419 (2012).

19. McDonald, K.G. et al. Epithelial expression of the cytosolic retinoid chaperone cellular retinol binding protein II is essential for in vivo imprinting of local gut dendritic cells by lumenal retinoids. Am. J. Pathol. 180, 984-997 (2012).

20. Borel, P. et al. Processing of vitamin $A$ and $E$ in the human gastrointestinal tract. Am. J. Physiol. Gastrointest. Liver Physiol. 280, G95-G103 (2001).

21. Napoli, J.L. Biosynthesis and metabolism of retinoic acid: roles of CRBP and CRABP in retinoic acid: roles of CRBP and CRABP in retinoic acid homeostasis. J. Nutr. 123 (2 Suppl), 362-366 (1993).

22. O'Byrne, S.M. \& Blaner, W.S. Retinol and retinyl esters: biochemistry and physiology. J. Lipid Res. 54, 1731-1743 (2013).

23. Iliev, I.D. et al. Human intestinal epithelial cells promote the differentiation of tolerogenic dendritic cells. Gut 58, 1481-1489 (2009).

24. Wagner, M., Han, B. \& Jessell, T.M. Regional differences in retinoid release from embryonic neural tissue detected by an in vitro reporter assay. Development 116, 55-66 (1992).

25. Uematsu, S. et al. Regulation of humoral and cellular gut immunity by lamina propria dendritic cells expressing Toll-like receptor 5. Nat. Immunol. 9, 769-776 (2008)

26. Bimczok, D. et al. Human primary gastric dendritic cells induce a Th1 response to H. pylori. Mucosal Immunol 3, 260-269 (2010).

27. Meredith, M.M. et al. Expression of the zinc finger transcription factor zDC (Zbtb46, Btbd4) defines the classical dendritic cell lineage. J. Exp. Med. 209, 1153-1165 (2012).

28. Yokota, A. et al. GM-CSF and IL-4 synergistically trigger dendritic cells to acquire retinoic acid-producing capacity. Int. Immunol. 21, 361-377 (2009).

29. Iwata, M., Hirakiyama, A., Eshima, Y., Kagechika, H., Kato, C. \& Song, S.Y. Retinoic acid imprints gut-homing specificity on Tcells. Immunity 21, 527538 (2004)

30. Michetti, M., Kelly, C.P., Kraehenbuhl, J.P., Bouzourene, H. \& Michetti, P. Gastric mucosal alpha(4)beta(7)-integrin-positive CD4 T lymphocytes and immune protection against helicobacter infection in mice. Gastroenterology 119, 109-118 (2000).

31. Segal, E.D., Lange, C., Covacci, A., Tompkins, L.S. \& Falkow, S. Induction of host signal transduction pathways by Helicobacter pylori. Proc. Natl. Acad. Sci. USA 94, 7595-7599 (1997).

32. Bamford, K.B. et al. Lymphocytes in the human gastric mucosa during Helicobacter pylori have a T helper cell 1 phenotype. Gastroenterology 114, 482-492 (1998).

33. Harris, P.R. et al. Helicobacter pylori gastritis in children is associated with a regulatory T-cell response. Gastroenterology 134, 491-499 (2008).

34. Robinson, K. et al. Helicobacter pylori-induced peptic ulcer disease is associated with inadequate regulatory T cell responses. Gut 57, 13751385 (2008).

35. Serrano, C. et al. Downregulated Th17 responses are associated with reduced gastritis in Helicobacter pylori-infected children. Mucosal Immunol 6, 950-959 (2013).

36. Lampen, A., Meyer, S., Arnhold, T. \& Nau, H. Metabolism of vitamin A and its active metabolite all-trans-retinoic acid in small intestinal enterocytes. $J$. Pharmacol. Exp. Ther. 295, 979-985 (2000).

37. McGrane, M.M. Vitamin A regulation of gene expression: molecular mechanism of a prototype gene. J Nutr. Biochem. 18, 497-508 (2007).

38. Tang, X.H. \& Gudas, L.J. Retinoids, retinoic acid receptors, and cancer. Annu. Rev. Pathol 6, 345-364 (2011).

39. Strate, I., Min, T.H., lliev, D. \& Pera, E.M. Retinol dehydrogenase 10 is a feedback regulator of retinoic acid signalling during axis formation and 
patterning of the central nervous system. Development 136, 461-472 (2009).

40. Pinaire, J. et al. Identification of a retinoid receptor response element in the human aldehyde dehydrogenase-2 promoter. Alcohol Clin. Exp. Res. 27, 1860-1866 (2003).

41. Sun, C.M. et al. Small intestine lamina propria dendritic cells promote de novo generation of Foxp3 T reg cells via retinoic acid. J.Exp.Med. 204, 1775-1785 (2007).

42. Coombes, J.L. et al. A functionally specialized population of mucosal CD103 + DCs induces Foxp3 + regulatory T cells via a TGF-beta and retinoic acid-dependent mechanism. J. Exp. Med. 204, 1757-1764 (2007).

43. Iliev, I.D., Mileti, E., Matteoli, G., Chieppa, M. \& Rescigno, M. Intestinal epithelial cells promote colitis-protective regulatory T-cell differentiation through dendritic cell conditioning. Mucosal Immunol 2, 340-350 (2009).

44. Manicassamy, S. et al. Toll-like receptor 2-dependent induction of vitamin A-metabolizing enzymes in dendritic cells promotes Tregulatory responses and inhibits autoimmunity. Nat. Med 15, 401-409 (2009).

45. Szatmari, I. et al. PPARgamma controls CD1d expression by turning on retinoic acid synthesis in developing human dendritic cells. J. Exp. Med. 203, 2351-2362 (2006).

46. Nagy, T.A. et al. Helicobacter pylori induction of eosinophil migration is mediated by the cag pathogenicity island via microbial-epithelial interactions. Am. J. Pathol. 178, 1448-1452 (2011).

47. Harrison, E.H. Mechanisms of digestion and absorption of dietary vitamin A. Annu. Rev. Nutr. 25, 87-103 (2005).

48. Cassani, B., Villablanca, E.J., De Calisto, J., Wang, S. \& Mora, J.R. Vitamin A and immune regulation: role of retinoic acid in gut-associated dendritic cell education, immune protection and tolerance. Mol. Aspects Med. 33, 63-76 (2012).

49. Watchmaker, P.B. et al. Comparative transcriptional and functional profiling defines conserved programs of intestinal DC differentiation in humans and mice. Nat. Immunol. 15, 98-108 (2014).
50. Robinson, P.W., Green, S.J., Carter, C., Coadwell, J. \& Kilshaw, P.J. Studies on transcriptional regulation of the mucosal T-cell integrin alphaEbeta7 (CD103). Immunology 103, 146-154 (2001).

51. Guilliams, M. et al. Skin-draining lymph nodes contain dermis-derived CD103(-) dendritic cells that constitutively produce retinoic acid and induce Foxp3(+) regulatory T cells. Blood 115, 1958-1968 (2010).

52. Epplein, M. et al. Helicobacter pylori prevalence and circulating micronutrient levels in a low-income United States population. Cancer Prev. Res. (Phila) 4, 871-878 (2011).

53. Ozturk, Y., Buyukgebiz, B., Arslan, N., Ozer, E. \& Lebe, B. Serum vitamin $A$ and total carotene concentrations in well-nourished children with Helicobacter pylori infection. J. Pediatr. Gastroenterol. Nutr. 36, 502-504 (2003).

54. Hu, K.W., Chen, F.H., Ge, J.F., Cao, L.Y. \& Li, H. Retinoid receptors in gastric cancer: expression and influence on prognosis. Asian Pac. J. Cancer Prev. 13, 1809-1817 (2012).

55. Kim, J.H., Choi, Y.K., Kwon, H.J., Yang, H.K., Choi, J.H. \& Kim, D.Y. Downregulation of gelsolin and retinoic acid receptor beta expression in gastric cancer tissues through histone deacetylase 1. J. Gastroenterol. Hepatol. 19, 218-224 (2004).

56. Smoot, D.T., Sewchand, J., Young, K., Desbordes, B.C., Allen, C.R. \& Naab, T. A method for establishing primary cultures of human gastric epithelial cells. Methods Cell. Sci 22, 133-136 (2000).

57. Bimczok, D. et al. Helicobacter pylori infection inhibits phagocyte clearance of apoptotic gastric epithelial cells. J. Immunol. 190, 66266634 (2013).

58. Sun, X. et al. TLR2 mediates Helicobacter pylori-induced tolerogenic immune response in mice. PLoS One 8, e74595 (2013).

59. Pfaffl, M.W. A new mathematical model for relative quantification in realtime RT-PCR. Nucleic Acids Res. 29, e45 (2001).

60. Napoli, J.L. \& Horst, R.L. Quantitative analyses of naturally occurring retinoids. Methods Mol. Biol. 89, 29-40 (1998). 